\title{
Osteopontin is highly susceptible to cleavage in bovine milk and the proteolytic fragments bind the $\alpha_{\mathrm{v}} \beta_{3}$-integrin receptor
}

\author{
B. Christensen and E. S. Sørensen ${ }^{1}$ \\ Department of Molecular Biology and Genetics, Aarhus University, DK-8000 Aarhus, Denmark
}

\begin{abstract}
Site-specific and partial proteolysis of milk proteins can both alter and increase their biological activity. The milk protein osteopontin (OPN) is a highly phosphorylated integrin-binding molecule present in most tissues and body fluids. Osteopontin is a biological substrate for matrix metalloproteinases, thrombin, plasmin, and cathepsin D. These proteases cleave OPN at several positions near the integrin-binding sequence Arg-Gly$\mathrm{Asp}^{138}$. This cleavage can either increase or reduce the ability of OPN to bind integrins and illustrates that small differences in the cleavage pattern can have a substantial effect on the functionality of OPN. Bovine milk OPN (bOPN) exists in both intact full-length and cleaved forms, and in this study, $6 \mathrm{~N}$-terminal bOPN fragments originating from proteolytic cleavage were purified and characterized by mass spectrometry. These fragments were generated by cleavage at the Lys ${ }^{145}$ -

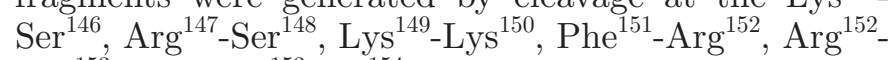
$\mathrm{Arg}^{153}$, and $\mathrm{Arg}^{153}{ }_{\text {-Ser }}{ }^{154}$ peptide bonds. The principal protease in milk, plasmin, appeared to cleave 3 of these sites. However, the major cleavage site was observed to be at the Phe ${ }^{151}-\mathrm{Arg}^{152}$ bond, which does not match the specificity of plasmin. The bOPN fragments were shown to interact with the integrin receptor $\alpha_{V} \beta_{3}$ as efficiently as the well-characterized and highly active OPN fragment Ile ${ }^{1}-\mathrm{Arg}^{152}$, generated by thrombin cleavage of human milk OPN. These data show that OPN in milk is highly susceptible to proteolytic cleavage in the region containing the integrin-binding motifs, and the generated fragments are highly capable of binding cells via the $\alpha_{\mathrm{V}} \beta_{3}$-integrin.
\end{abstract}

Key words: osteopontin, proteolytic cleavage, integrin, cell binding

\section{INTRODUCTION}

Osteopontin (OPN) is an acidic highly phosphorylated protein that contains several integrin-binding

\footnotetext{
Received July 3, 2013.

Accepted October 6, 2013.

${ }^{1}$ Corresponding author: ess@mb.au.dk
}

motifs, including the Arg-Gly-Asp (RGD) sequence. Osteopontin is a central protein in a variety of physiological processes, such as bone remodeling, inhibition of ectopic calcification, tumor growth, and immune modulatory functions (Sodek et al., 2000; Wang and Denhardt, 2008; Anborgh et al., 2010). Many of the functions propagated by OPN are mediated through interactions with integrin receptors. The $\alpha_{\mathrm{v}} \beta_{6^{-}}, \alpha_{5} \beta_{1^{-}}$, $\alpha_{8} \beta_{1^{-}}, \alpha_{\mathrm{v}} \beta_{1^{-}}, \alpha_{\mathrm{v}} \beta_{5^{-}}$, and $\alpha_{\mathrm{v}} \beta_{3^{-} \text {-integrins recognize OPN }}$ through the conserved RGD sequence (Yokosaki et al., 2005; Kazanecki et al., 2007a). Especially, the widely expressed $\alpha_{V} \beta_{3}$-integrin is a well-characterized receptor for OPN in processes such as cell adhesion, migration, and IL-12 expression (Ashkar et al., 2000; Christensen et al., 2010; Ek-Rylander and Andersson, 2010). The integrins $\alpha_{4} \beta_{1}$ and $\alpha_{9} \beta_{1}$ bind OPN independently of the RGD sequence via the motif SVVYGLR (in human OPN), which is exposed by thrombin cleavage of the protein (Yokosaki et al., 1999; Bayless and Davis, 2001), and the monocyte $\alpha_{X} \beta_{2}$-integrin receptor interacts with highly acidic parts of OPN (Schack et al., 2009b).

Osteopontin is a secreted protein synthesized by a variety of cell types and found in most tissues and body fluids, such as blood, urine, and milk (Sodek et al., 2000). The concentration of OPN in milk is particularly high, as approximately 18 and $138 \mathrm{mg} / \mathrm{L}$ have been reported in bovine and human milk, respectively (Schack et al., 2009a). In comparison, the amounts of OPN in plasma and urine have been measured to be approximately $35 \mu \mathrm{g} / \mathrm{L}$ and 3 to $4 \mathrm{mg} / \mathrm{L}$ (Schack et al., 2009a; Kolbach et al., 2012). Although OPN is very abundant in milk, its biological function in milk is not well characterized. Osteopontin has been implicated in mammary gland development and differentiation (Nemir et al., 2000) and it has also been shown to interact with the milk protein lactoferrin and hypothesized to act as a transporter of this immunomodulating and antimicrobial protein to its site of action (Yamniuk et al., 2009). Furthermore, OPN can inhibit the formation of renal stones by inhibiting growth and aggregation of calcium crystals (Hoyer et al., 2001) and, thus, the protein could potentially also inhibit unintentional calcium crystallization and precipitation in milk (Holt et al., 2009). Osteopontin can also act as an opsonin in 
milk, as it binds directly to several bacteria strains in a calcium-dependent interaction, leading to enhanced phagocytosis via the $\alpha_{X} \beta_{2}$-integrin receptor (Schack et al., 2009b). Furthermore, ingested milk OPN may modulate the immune system at the gut mucosal surface of infants, as the protein is relatively resistant to proteolysis by neonatal gastric juice and can induce the expression of IL-12 from human intestinal lamina propria mononuclear cells (Chatterton et al., 2004; Schack et al., 2009a). Even though a considerable proportion of ingested OPN is likely to be digested by duodenal and gastric proteases, feeding studies have demonstrated that OPN can be found in the small intestine, plasma, and feces of mice (da Silva et al., 2009; Ge et al., 2013). Thus, a fraction of the OPN survives the passage though the digestive system, and can potentially exert its function at the gut mucosal surfaces.

Osteopontin is extensively altered through posttranslational modification, such as phosphorylation, glycosylation, and proteolytic processing, which has significant implications on the functionality of the protein (Keykhosravani et al., 2005; Kazanecki et al., 2007b; Christensen et al., 2010). Osteopontin is extensively phosphorylated in both bovine and human milk, where the protein is decorated by approximately 25 to 30 phosphate groups (Sørensen et al., 1995; Christensen et al., 2005). In comparison, OPN from urine and the bone matrix only contains approximately 8 and 10 phosphorylations, respectively (Keykhosravani et al., 2005; Christensen et al., 2008). Both bovine milk OPN (bOPN) and human milk OPN (hOPN) contain $O$-glycosylated threonines in an unphosphorylated region close to the RGD sequence, but the structure of the glycans differ significantly between bOPN and hOPN (Kumura et al., 2004; Christensen et al., 2012). Furthermore, hOPN is present as an intact protein and in several cleaved forms, which among others, result from cathepsin D and plasmin cleavage (Senger et al., 1989; Sørensen et al., 2003; Christensen et al., 2010). In particular, 7 cleavage sites adjacent to the integrin binding RGD sequence have been identified in hOPN (Christensen et al., 2010). The presence of N-terminal bOPN fragments have also been observed in bovine milk; however, the exact cleavage sites have not been identified (Kumura et al., 2004; Bissonnette et al., 2012). Thus, the cleavage pattern observed for hOPN in milk is not necessarily identical to that for bOPN; for instance, the important thrombin and plasmin cleavage sites are not similar between the human and bovine OPN sequences (Christensen et al., 2010). Knowledge of the exact cleavage sites is important, as small differences in the C-terminal of the fragments may have significant effects on the interaction between these and integrins. For instance, the $\alpha_{5} \beta_{1^{-}}$and $\alpha_{9} \beta_{1^{-}}$ integrins can bind thrombin-cleaved but not matrix metalloproteinase-cleaved OPN, although their cleavage sites are only separated by 2 amino acids (Yokosaki et al., 2005). Likewise, RGD-dependent cell binding of fibroblast-like synoviocytes to thrombin-cleaved OPN is abrogated upon removal of a single C-terminal arginine residue by carboxypeptidase B (Sharif et al., 2009). In addition, the $\alpha_{V} \beta_{3}$-integrin binds strongly to thrombinand plasmin-cleaved hOPN, whereas the binding after cathepsin D cleavage is negligible, although all these proteases cleave within 4 adjacent amino acids (Christensen et al., 2010).

In the present study, we have purified and characterized N-terminal bOPN fragments from bovine milk. In total, 6 different cleavage sites in the region $\operatorname{Lys}^{145}-\mathrm{Arg}^{153}$ next to the integrin-binding RGD ${ }^{138}$ sequence were identified. Interestingly, bOPN appeared to be most susceptible to cleavage at the $\mathrm{Phe}^{151}-\mathrm{Arg}^{152}$ peptide bond, which does not match the cleavage site for thrombin, plasmin, cathepsin $\mathrm{D}$, or matrix metalloproteinases previously reported to cleave OPN in vivo. Furthermore, cleaved bOPN fragments mediated cell adhesion via the $\alpha_{V} \beta_{3}$-integrin, as efficiently as that mediated by the highly active hOPN fragment $\mathrm{Ile}^{1}$ $\mathrm{Arg}^{152}$, generated by thrombin cleavage. This shows that bovine milk contains several bioactive $\mathrm{N}$-terminal fragments of OPN, with the predominating fragment being $\mathrm{Ile}^{1}-\mathrm{Phe}^{151}$.

\section{MATERIALS AND METHODS}

\section{Purification of OPN}

Bovine OPN was purified from bovine milk essentially as described previously (Sørensen and Petersen, 1993a) and subjected to gel filtration on a Superdex 200 HR-10/30 column (GE Healthcare, Uppsala, Sweden) to separate the full-length protein from the $\mathrm{N}$ terminal fragments. The column was equilibrated with $0.1 M$ ammonium bicarbonate ( $\mathrm{pH} 8.0$ ) and operated at a flow rate of $5 \mathrm{~mL} / \mathrm{h}$. Proteins were monitored by measuring the effluent at $230 \mathrm{~nm}$. The collected fractions were analyzed by N-terminal sequencing on a PROCISE HT protein sequencer (Applied Biosystems Ltd., Warrington, UK), mass spectrometry as described below and SDS-PAGE. Human OPN was purified from breast milk, and the full-length protein was separated from N-terminal fragments as described (Christensen et al., 2010).

\section{Characterization of bOPN and Derived Fragments}

Determination of High-Molecular-Weight Masses. Full-length bOPN and N-terminal fragments 
purified from bovine milk were analyzed by matrixassisted laser desorption ionization mass spectrometry (MALDI-MS) using a Voyager DE-PRO MALDI time-of-flight mass spectrometer (Applied Biosystems Ltd.). Samples for MS analyses were prepared by mixing the sample with a saturated solution of 2,5-dihydroxybenzoic acid in a 1:1 ratio directly on the MS-target probe. All spectra were obtained in positive linear-ion mode using a nitrogen laser at $337 \mathrm{~nm}$ and an acceleration voltage of $20 \mathrm{kV}$. Typically, 50 to 100 laser shots were added per spectrum and calibrated with external standards.

Determination of the C-Terminal of bOPN Fragments. Full-length bOPN and N-terminal fragments were digested with endoproteinase Asp-N (SigmaAldrich, St. Louis, MO) using an enzyme-to-substrate ratio of 1:75 (wt/wt) in $50 \mathrm{~m} M$ sodium phosphate buffer ( $\mathrm{pH} 8.0$ ) containing $50 \% \mathrm{H}_{2}{ }^{18} \mathrm{O}$ (Sigma-Aldrich) at $37^{\circ} \mathrm{C}$ for $18 \mathrm{~h}$ and with chymotrypsin (Sigma-Aldrich) using an enzyme-to-substrate ratio of 1:30 (wt/wt) in $0.1 \mathrm{M}$ ammonium bicarbonate containing $50 \% \mathrm{H}_{2}{ }^{18} \mathrm{O}$ at $37^{\circ} \mathrm{C}$ for $1 \mathrm{~h}$. The resulting peptides were desalted and concentrated on a Zip-tip column containing $\mathrm{C}_{18}$ reversed-phase material (Millipore Corp., Bedford, MA) and analyzed by MALDI-MS in positive reflectorion mode.

For further analyses, endoproteinase Asp- $\mathrm{N}$ digests of N-terminal bOPN fragments were separated by reversed-phase HPLC (RP-HPLC) on a narrow-bore $\mathrm{C}_{2} / \mathrm{C}_{18}$ PC 2.1/10 column connected to a GE Healthcare SMART system. Separation was carried out in $0.1 \%$ trifluoroacetic acid (TFA; buffer A) and eluted with a gradient of $60 \%$ acetonitrile in $0.1 \%$ TFA (buffer B) developed over 54 min (0-9 min: 0\% buffer B; 9-49 min: 0-50\% buffer B; 49-54 min: $50-100 \%$ buffer B) at a flow rate of $0.15 \mathrm{~mL} / \mathrm{min}$. The peptides were detected in the effluent by measuring the absorbance at $214 \mathrm{~nm}$. Peptides were characterized by MALDIMS. The theoretical masses of proteins, fragments and peptides were calculated using the GPMAW program (Lighthouse Data, Odense, Denmark).

Plasmin and Thrombin Cleavage of OPN. Fulllength bOPN was digested with plasmin (Roche Applied Science, Indianapolis, IN; $0.15 \mathrm{mU} / \mu \mathrm{g}$ of OPN) in $0.1 \mathrm{M}$ ammonium bicarbonate at $37^{\circ} \mathrm{C}$ for $1 \mathrm{~h}$. The plasmin digest was fractionated by RP-HPLC as described above or by gel filtration on a Superdex 75 PC 3.2/30 column connected to a GE Healthcare SMART system. The gel filtration column was equilibrated with $0.1 M$ ammonium bicarbonate and operated at a flow rate of $0.05 \mathrm{~mL} / \mathrm{min}$. All fractions from the separations were analyzed by MALDI-MS in both positive reflector-ion and positive linear-ion mode and amino acid sequence analyses.
Human milk OPN was digested with thrombin (Sigma-Aldrich; $30 \mathrm{mU} / \mu \mathrm{g}$ of OPN) in $0.1 \mathrm{M}$ ammonium bicarbonate at $37^{\circ} \mathrm{C}$ for $1 \mathrm{~h}$. The generated fragments were separated by RP-HPLC as described above and were analyzed by MALDI-MS. The fraction containing the N-terminal hOPN fragment of interest was lyophilized and used for adhesion assays.

\section{Cell Adhesion Assays}

The MDA-MB-435 human cancer cell line (a kind gift from David T. Denhardt, Rutgers University, NJ) was maintained in Dulbecco's modified Eagle's Medium with GlutaMAX (Invitrogen Ltd., Paisley, UK) supplemented with $10 \%$ fetal bovine serum, and $1 \%$ antibiotics (penicillin/streptomycin). Flat-bottom 96well tissue culture treated polystyrene microtiter plates (Corning Inc., Corning, NY) were coated with $100 \mu \mathrm{L}$ of full-length hOPN, purified N-terminal fragments of $\mathrm{bOPN}$ and hOPN, and thrombin-cleaved hOPN $(5 \mu \mathrm{g} /$ $\mathrm{mL}$ ) in PBS at $4^{\circ} \mathrm{C}$ overnight and then blocked with $1 \%$ BSA. The MDA-MB-435 cells were trypsinized and then washed twice and resuspended to $5 \times 10^{5}$ cells/ $\mathrm{mL}$ in Dulbecco's modified Eagle's Medium containing $1 \mathrm{mg}$ of $\mathrm{BSA} / \mathrm{mL}$. For blocking of integrin function, cells were incubated for $30 \mathrm{~min}$ at $37^{\circ} \mathrm{C}$ in the presence of neutralizing antibodies against the $\alpha_{\mathrm{v}} \beta_{3}$-integrin (clone LM609; Millipore Corp.) at a concentration of $5 \mu \mathrm{g} / \mathrm{mL}$ or an IgG1 isotype control mAb (MOPC21; Sigma-Aldrich). Subsequently, cells $(100 \mu \mathrm{L})$ were added to coated wells and incubated for $2 \mathrm{~h}$ at $37^{\circ} \mathrm{C}$ in a humidified atmosphere with $5 \% \mathrm{CO}_{2}$. Non-adhered cells were removed by washing twice with $75 \mu \mathrm{L}$ Percoll (Sigma-Aldrich; $73 \%$ Percoll and $0.9 \% \mathrm{NaCl}$ ) and adherent cells were fixed with $50 \mu \mathrm{L}$ of fixative $(10 \%$ glutaraldehyde in Percoll). Fixed cells were stained with $100 \mu \mathrm{L}$ of $0.5 \%$ toluidine blue and solubilized in $50 \mu \mathrm{L}$ of $0.5 \%$ Triton X-100 before reading at $630 \mathrm{~nm}$ using a microplate autoreader.

\section{RESULTS}

\section{Purification and Analysis of Bovine Milk OPN}

Osteopontin was purified from bovine milk and analyzed by SDS-PAGE. This revealed the presence of 2 components migrating at approximately 35 and 50 $\mathrm{kDa}$ (Figure 1A, lane 2). Edman sequencing showed the sequence LPVKP, corresponding to the N-terminal of bOPN for both components. The components were separated by gel filtration (data not shown), and analyzed by SDS-PAGE (Figure 1A, lanes 3 and 4) and by linear MALDI-MS (Figure 1B). The MALDI-MS showed molecular masses of approximately 19.8 and 
A

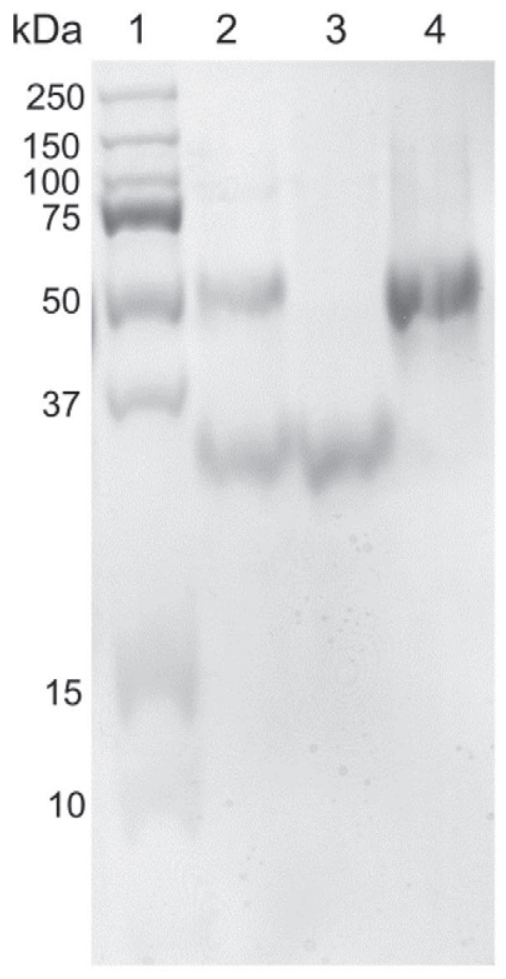

$\mathrm{B}$
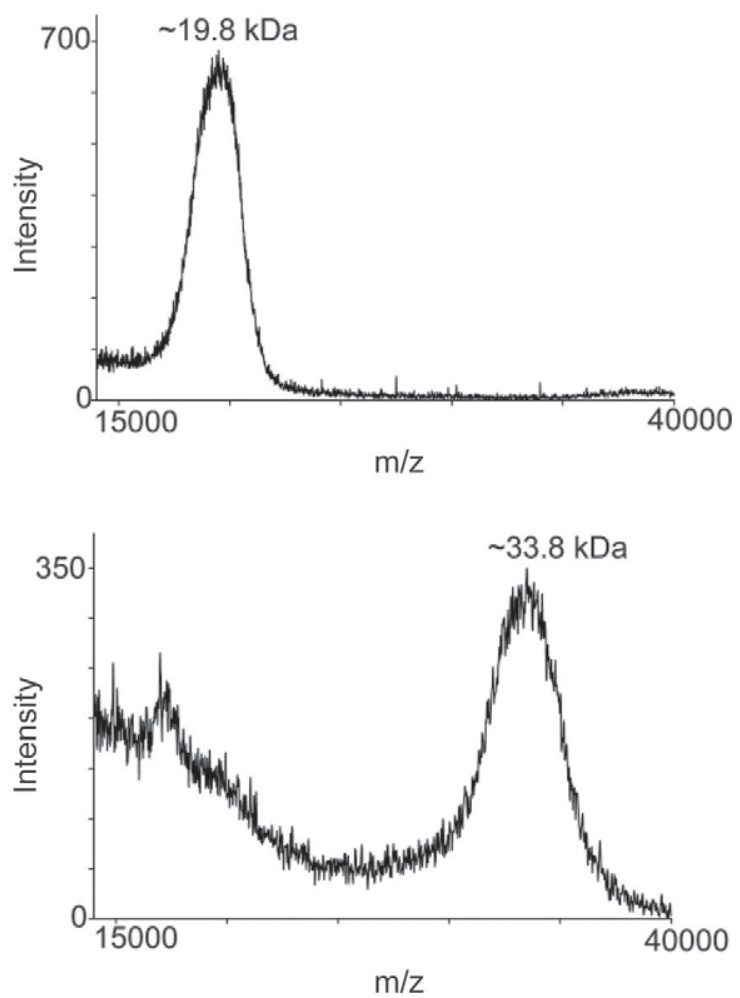

Figure 1. Analysis of bovine milk osteopontin (OPN). (A) The proteins were separated on a 14\% Tris-glycine gel by SDS-PAGE and visualized by Coomassie Brilliant Blue staining. Lane 1 = molecular weight standards; lane 2 = bovine OPN (bOPN) purified from milk; lanes 3 and $4=\mathrm{bOPN}$ after gel filtration. (B) Matrix-assisted laser desorption ionization mass spectrometry (MALDI-MS) of bOPN from lane 3 (upper spectra) and 4 (lower spectra) in (A). $m / z=$ mass-to-charge ratio.

$33.8 \mathrm{kDa}$ for the bOPN forms migrating at 35 and 50 $\mathrm{kDa}$ in SDS/PAGE, respectively. As the theoretical mass of the bovine OPN polypeptide without modifications is approximately 29,242 Da, the linear MS analysis combined with the $\mathrm{N}$-terminal sequencing indicated that the purified proteins were $\mathrm{N}$-terminal fragments of $\mathrm{bOPN}$ and the intact protein, respectively.

\section{Identification of Cleavage Sites in Bovine Milk OPN}

The exact cleavage sites in bOPN were identified by determination of the C-terminal amino acid sequence of the N-terminal bOPN fragments. Full-length bOPN (included as control) and the N-terminal fragments separated by gel filtration were subjected to C-terminal analysis by incubation with endoproteinase Asp-N or chymotrypsin in a buffer containing equal amounts of $\mathrm{H}_{2}{ }^{16} \mathrm{O}$ and $\mathrm{H}_{2}{ }^{18} \mathrm{O}$. Proteolysis in this buffer results in $50 \%$ incorporation of a ${ }^{16} \mathrm{O}$ - and ${ }^{18} \mathrm{O}$-atom in all generated peptides except for C-terminal peptides, which are not affected by the hydrolysis. The C-terminal peptides will, therefore, retain a normal isotopic distribution when analyzed by MALDI-MS, whereas a double signal spaced by 2 Da will be observed for all internal peptides (Schnölzer et al., 1996).

The MS analysis of full-length bOPN digested with chymotrypsin only showed internal peptides represented by the characteristic double signals spaced by 2 Da (Figure 2A), whereas the 2 peptides Glu ${ }^{143}-$ Phe $^{151}$ and $\mathrm{Glu}^{143}-\mathrm{Arg}^{152}$ were observed with normal isotopic distribution patterns in the chymotryptic digest of the N-terminal fragments (Figure 2B). Similarly, only peptides with the characteristic isotopic pattern of internal peptides appeared after Asp-N cleavage of full-length bOPN (Figure 2C). In contrast, the 4 peptides $\mathrm{Asp}^{138}$ $\mathrm{Lys}^{145}$, Asp ${ }^{138}-\mathrm{Arg}^{147}, \mathrm{Asp}^{138}-\mathrm{Phe}^{151}$, and $\mathrm{Asp}^{138}-\mathrm{Arg}^{152}$ in the Asp- $\mathrm{N}$ digest of the $\mathrm{N}$-terminal fragments were identified as C-terminal peptides (Figure 2D). The masses of the $\mathrm{C}$-terminal peptides observed in the 2 digests correspond to cleavage of bOPN in bovine milk after $\mathrm{Lys}^{145}, \mathrm{Arg}^{147}, \mathrm{Phe}^{151}$, and $\mathrm{Arg}^{152}$, respectively. The C-terminal peptide appearing with highest intensity in both N-terminal digests corresponded to cleavage of bOPN at the Phe ${ }^{151}-\mathrm{Arg}^{152}$ bond. 
A. Full-length bOPN + chymotrypsin

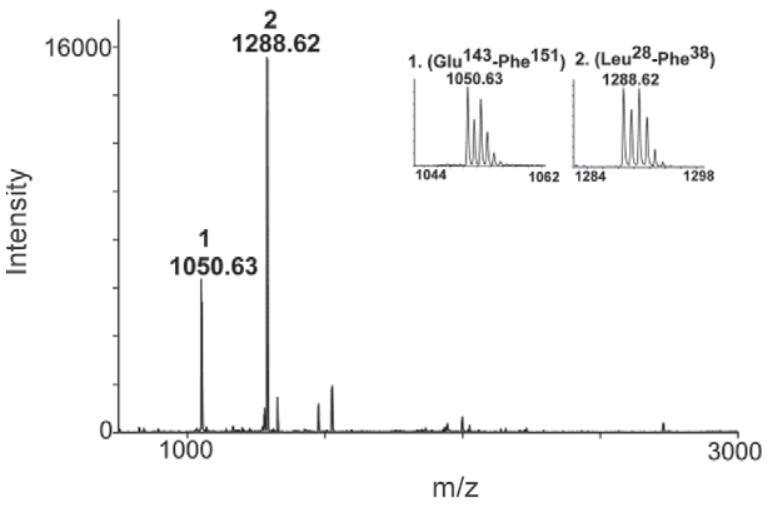

C. Full-length bOPN + Asp-N

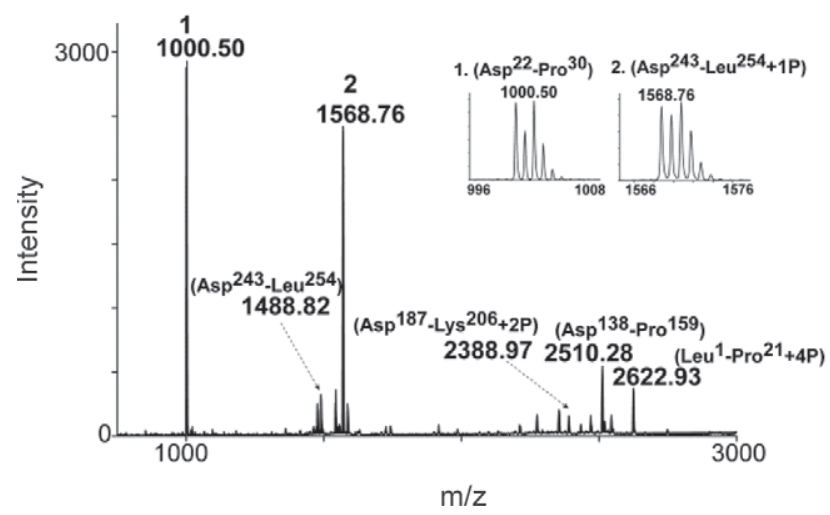

B. N-terminal bOPN + chymotrypsin

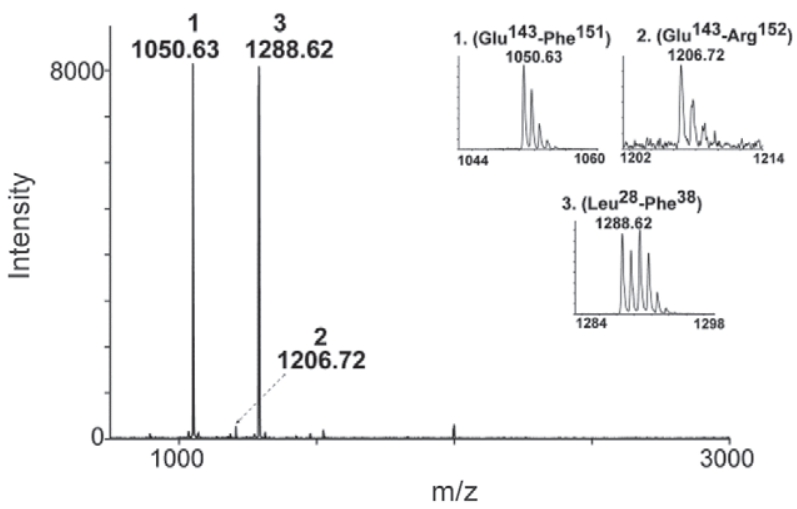

D. N-terminal bOPN + Asp-N

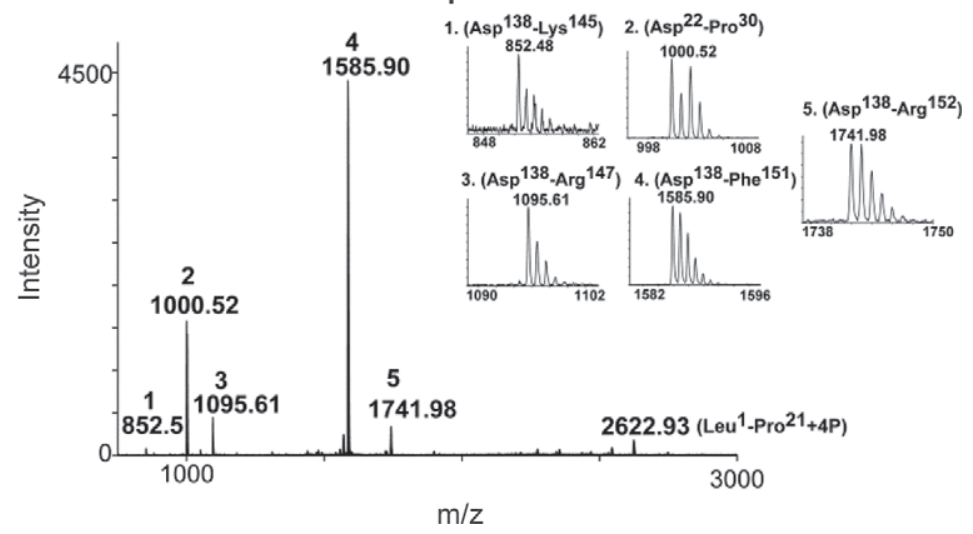

Figure 2. Matrix-assisted laser desorption ionization mass spectrometry (MALDI-MS) analysis of bovine milk osteopontin (OPN). Bovine OPN (bOPN) was digested with chymotrypsin and Asp-N in a buffer containing $50 \% \mathrm{H}_{2}{ }^{18} \mathrm{O}$ and analyzed by MALDI-MS without prior separation of the resulting peptides. In the MS spectra of full-length bOPN digested with chymotrypsin (A) or Asp-N (C), only peptides with the monoisotopic pattern characteristic of internal peptides caused by incorporation of ${ }^{18} \mathrm{O}$ were observed. In the MS analysis of N-terminal bOPN digested with chymotrypsin (B) or Asp-N (D), several C-terminal peptides with a normal isotopic pattern were observed. These correspond to cleavage at the C-terminus of $\mathrm{Lys}^{145}, \mathrm{Arg}^{147}, \mathrm{Phe}^{151}$, and $\mathrm{Arg}^{152}$ in bovine milk. Several internal peptides were also observed in the digests of $\mathrm{N}$-terminal bOPN. $m / z=$ mass-to-charge ratio.

To further verify the cleavage sites of bOPN in bovine milk and their relative abundance, an Asp-N digest of $\mathrm{N}$-terminal bOPN in $50 \% \mathrm{H}_{2}{ }^{18} \mathrm{O}$ was separated by RP-HPLC (Figure 3A) and all fractions were analyzed by MALDI-MS. Five fractions (F1 to F5 in Figure 3) contained peptides with a natural isotopic distribution, identifying them as C-terminal peptides and, as expected, most peptides were represented by double signals spaced by 2 Da, identifying them as internal peptides (fraction F6 in Figure 3B shows the MS spectra of a representative internal peak). The 4 cleavages after $\operatorname{Lys}^{145}, \operatorname{Arg}^{147}, \mathrm{Phe}^{151}$, and $\operatorname{Arg}^{152}$ (Figure 2 ) were verified in this experiment and 2 additional cleavages after $\mathrm{Lys}^{149}$ and $\mathrm{Arg}^{153}$ were observed. The MS data of the observed C-terminal peptides representing bOPN cleavage sites are summarized in Table 1. In the RP-HPLC chromatogram in Figure 3A, fraction F5 containing the peptide $\mathrm{Asp}^{138}-\mathrm{Phe}^{151}$ appeared with higher intensity than fractions F1 to F4, which contained the other C-terminal peptides. This further indicates that the predominant cleavage site in bOPN is at the $\mathrm{Phe}^{151}-\mathrm{Arg}^{152}$ bond. Collectively, 6 different cleavage sites of bOPN were identified, which all were located adjacent to the integrin-binding motifs (Figure $4 \mathrm{~A}$ ). The cleavage sites identified in bOPN in this study have also been identified in hOPN, except for the $\mathrm{Arg}^{152}-\mathrm{Arg}^{153}$ and $\mathrm{Arg}^{153}$-Ser ${ }^{154}$ cleavages (Figure 4B).

\section{Plasmin Cleavage of OPN}

Plasmin is the main endopeptidase in milk and has also been shown to cleave hOPN in human milk (Christensen et al., 2010). To investigate whether the bOPN fragments identified in bovine milk could be generated in vitro by plasmin, full-length bOPN was incubated with plasmin and the resulting fragments and peptides 
A

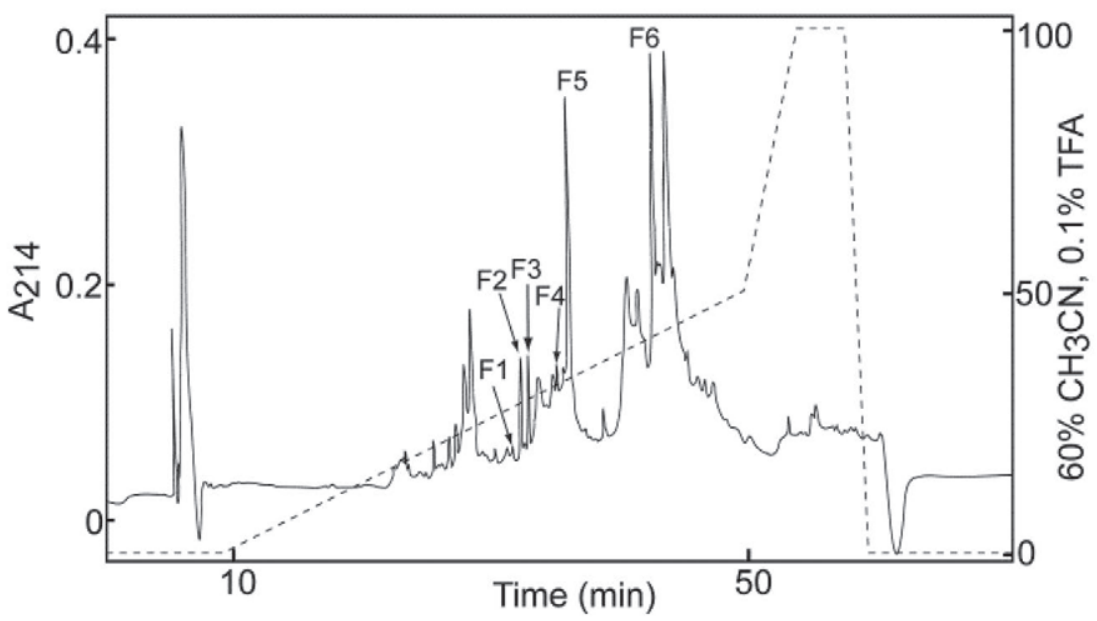

B
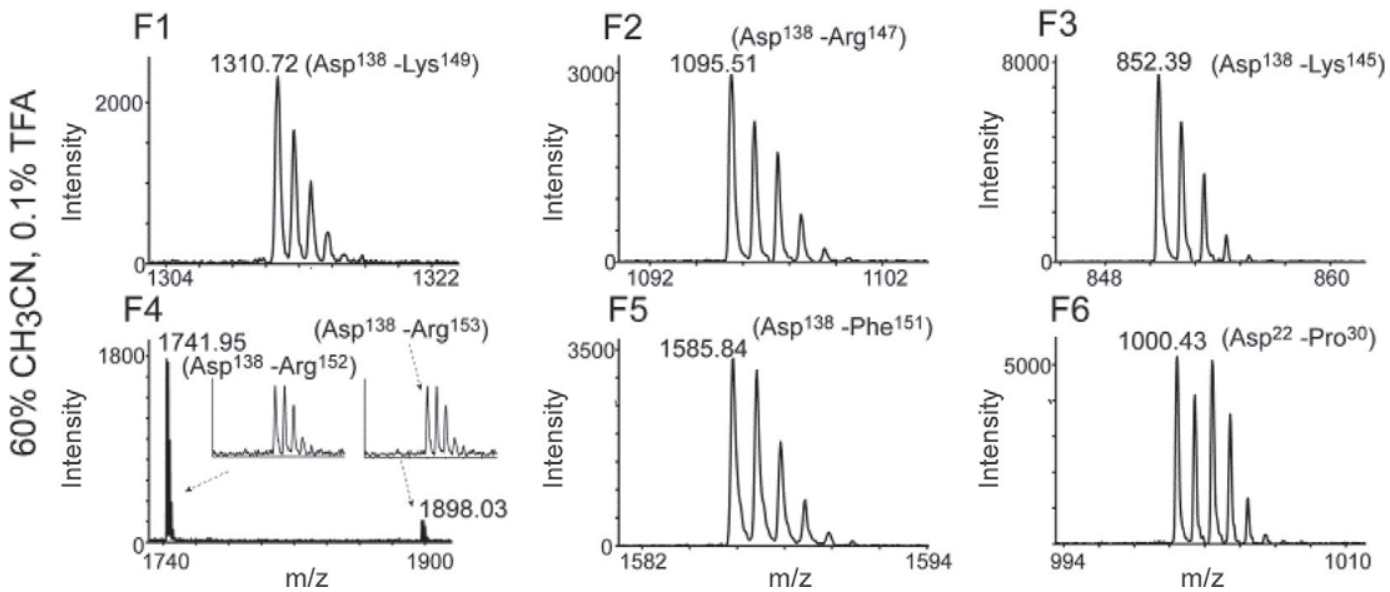

Figure 3. Reversed-phase HPLC (RP-HPLC) separation and MS analysis of N-terminal bovine osteopontin (bOPN) digested with Asp-N. (A) Peptides were separated by RP-HPLC on a $\mu$ RPC $C_{2} / C_{18}$ PC $2.1 / 10$ column operated by a GE Healthcare SMART system (GE Healthcare, Uppsala, Sweden). Separation was carried out in $0.1 \%$ trifluoroacetic acid (TFA) and peptides were eluted with a gradient of $60 \%$ acetonitrile in $0.1 \%$ TFA (dashed line) at a flow rate of $0.15 \mathrm{~mL} / \mathrm{min}$. The peptides were detected in the effluent by measuring the absorbance at $214 \mathrm{~nm}$ $\left(\mathrm{A}_{214}\right.$; solid line). (B) All fractions were analyzed by MS and representative data from fractions F1 to F6 are shown. Only the relevant $m / z$ (mass-to-charge ratio) region is shown. Peptides present in fractions F1 to F5 were identified as C-terminal peptides, as these retain their natural isotopic distribution. These correspond to cleavage of bOPN in bovine milk after Lys ${ }^{145}, \mathrm{Arg}^{147}, \mathrm{Lys}^{149}, \mathrm{Phe}^{151}, \mathrm{Arg}^{152}, \mathrm{and} \mathrm{Arg}^{153}$. In fraction F6, an internal peptide was identified based on the characteristic isotopic pattern caused by incorporation of ${ }^{18} \mathrm{O}$.

were separated by RP-HPLC or gel filtration (data not shown) and analyzed by MALDI-MS and N-terminal sequencing (Table 2). Two N-terminal fragments, Leu'$\mathrm{Lys}^{145}$ and $\mathrm{Leu}^{1}-\mathrm{Arg}^{147}$, were purified from the plasmin digest and both correspond to cleavage sites observed in bovine milk (F2 and F3 in Figure 4A). Based on signal intensity in MS, plasmin cleavage at Lys ${ }^{145}-\operatorname{Ser}^{146}$ is much more prevalent than cleavage at $\mathrm{Arg}^{147}-\mathrm{Ser}^{148}$. In addition, plasmin cleavage was observed at the $\operatorname{Arg}^{152}$ $\operatorname{Arg}^{153}$ bond, indicating that plasmin can also cleave bOPN at this position in bovine milk (F4 in Figure $4 \mathrm{~A})$.

\section{Cell-Binding Assay}

Cell binding to full-length hOPN through the $\alpha_{\mathrm{V}} \beta_{3^{-}}$ integrin has been shown to be at a relatively low level, whereas the binding to N-terminal fragments of hOPN purified from milk and in vitro thrombin-cleaved hOPN was at a significantly higher level (Christensen et al., $2010,2012)$. To test the ability of N-terminal bOPN fragments purified from bovine milk to interact with the $\alpha_{\mathrm{V}} \beta_{3}$-integrin, an adhesion assay was performed using the well-described hOPN forms from human milk, cleaved or uncleaved with thrombin, as a comparison. 
Table 1. Identified C-terminal peptides in the Asp-N digest of N-terminal bovine osteopontin (bOPN) fragments

\begin{tabular}{llcc}
\hline Fraction $^{1}$ & C-terminal peptide $^{2}$ & Measured $^{3}(\mathrm{Da})$ & Expected $^{4}(\mathrm{Da})$ \\
\hline F1 & DSVAYGLKSRSK $^{149}$ & $1,310.72$ & $1,310.70$ \\
F2 & DSVAYGLKSR $^{147}$ & $1,095.51$ & $1,095.57$ \\
F3 & DSVAYGLK $^{145}$ & 852.39 & 852.44 \\
F4 & DSVAYGLKSRSKKFR $^{152}$ & $1,741.95$ & $1,741.96$ \\
& DSVAYGLKSRSKKFR $^{153}$ & $1,898.03$ & $1,898.06$ \\
F5 & DSVAYGLKSRSKKF $^{151}$ & $1,585.84$ & $1,585.86$ \\
\hline
\end{tabular}

${ }^{1}$ Fractions from the Asp- $\mathrm{N}$ digest of N-terminal bOPN from bovine milk identified to contain C-terminal peptides (see Figure 3).

${ }^{2}$ The C-terminal peptides identified by matrix-assisted laser desorption ionization mass spectrometry (MALDIMS).

${ }^{3}$ Mesured monoisotopic masses $\left(\mathrm{MH}^{+}\right)$determined by MALDI-MS.

${ }^{4}$ Expected masses $\left(\mathrm{MH}^{+}\right)$were calculated using the GPMAW software (Lighthouse Data, Odense, Denmark).

The adhesion of MDA-MB-435 cells to OPN was completely blocked by an anti- $\alpha_{\mathrm{V}} \beta_{3}$ antibody, but not affected by an isotype IgG control (Figure 5), showing that virtually all binding of these cells to OPN was dependent on this integrin receptor. A comparison of $\mathrm{N}$-terminal bOPN and hOPN fragments purified from bovine and human milk showed that the cells exhibited approximately $30 \%$ higher levels of adhesion to cleaved bOPN forms compared with the cleaved hOPN. The purified N-terminal bOPN fragments mediated cell ad- hesion at the same high level as the well-characterized and highly active hOPN fragment $\mathrm{Ile}^{1}-\mathrm{Arg}^{152}$ resulting from thrombin cleavage.

\section{DISCUSSION}

Osteopontin has recently been reported to be cleaved in bovine milk using proteomic analysis and immunoblotting; however, the exact cleavage sites were not identified, although it was suggested that the protein

A

LPVKPTSSGSSEEKQLNNKYPDAVATWLKPDPSQKQTFLAPQNSVSSEETDDNKQNTL 58

TLPSKSNESPEQTDDLDDDDDNSQDVNSNDSDDAETTDDPDHSDESHHSDESDEVDFP 114

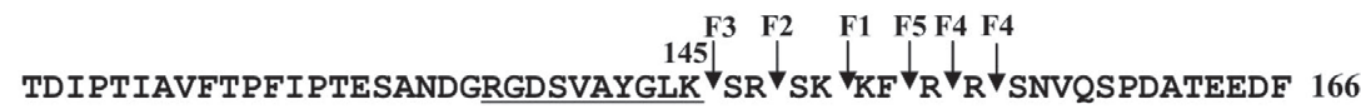

TSHIESEEMHDAPKKTSQLTDHSKETNSSELSKELTPKAKDKNKHSNLIESQENSKLS 224

QEFHSLEDKLDLDHKSEEDKHLKIRISHELDSASSEVN 262

B

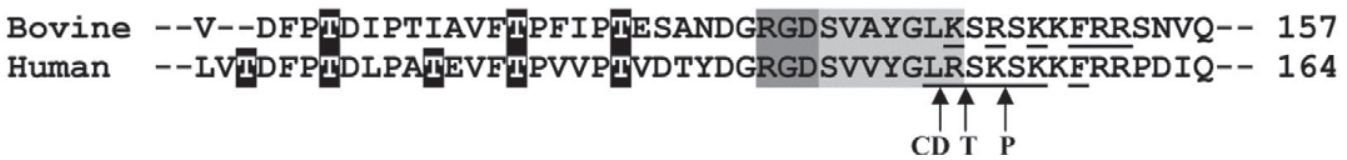

Figure 4. Identified cleavage sites in bovine milk osteopontin (OPN). (A) The identified cleavage sites in fractions F1 to F5 in Figure 3 are shown with arrows. They are all located adjacent to the integrin-binding Arg-Gly-Asp (RGD) sequence and the cryptic integrin-binding site SVAYGLK, which are underlined. (B) Alignment of bovine and human OPN (bOPN and hOPN, respectively) sequences. Amino acids that have been shown to constitute C-terminal residues and thereby represent cleavage sites in hOPN (Christensen et al., 2010) and bOPN are underlined. Major proteolytic cleavage sites for cathepsin D (CD), and thrombin (T) and plasmin (P) in hOPN (Christensen et al., 2010) are indicated by arrows. The integrin-binding motifs RGD and SVVYGLR are highlighted in gray. 
Table 2. Characterization of bovine osteopontin (bOPN) fragments generated by plasmin

\begin{tabular}{|c|c|c|c|}
\hline $\begin{array}{l}\text { Osteopontin } \\
\text { fragment }^{1}\end{array}$ & Measured $^{2}$ (Da) & Expected $^{3}(\mathrm{Da})$ & Difference $^{4}(\mathrm{Da})$ \\
\hline $\mathrm{Leu}^{1}-\mathrm{Lys}^{35}$ & $4,164.65^{5}$ & $3,842.29$ & $322.36(4 \mathrm{P})$ \\
\hline Leu $^{1}$-Lys ${ }^{1456}$ & $19,400^{5}$ & 15,817 & $3,583(\mathrm{P} / \mathrm{G})$ \\
\hline $\mathrm{Leu}^{1}-\mathrm{Arg}^{1476}$ & $19,400^{5}$ & 16,061 & $3,339(\mathrm{P} / \mathrm{G})$ \\
\hline $\operatorname{Arg}^{153}-$ Lys $^{180}$ & $3,426.18$ & $3,186.38$ & $239.80(3 \mathrm{P})$ \\
\hline $\operatorname{Arg}^{153}{ }^{15 y s}{ }^{181}$ & $3,474.33$ & $3,314.48$ & $159.85(2 \mathrm{P})$ \\
\hline $\operatorname{Arg}^{153}-\mathrm{Lys}^{204}$ & $6,258.40^{5}$ & $5,859.23$ & $399.17(5 \mathrm{P})$ \\
\hline $\mathrm{Arg}^{153}-\mathrm{Lys}^{210}$ & $6,941.39^{5}$ & $6,544.02$ & $397.37(5 \mathrm{P})$ \\
\hline $\mathrm{Ala}^{205}{ }^{-\mathrm{Lys}^{247}}$ & $5,398.91^{5}$ & $5,074.52$ & $324.39(4 \mathrm{P})$ \\
\hline $\mathrm{Asn}^{209}-\mathrm{Lys}^{247}$ & $4,954.68^{5}$ & $4,632.01$ & $322.67(4 \mathrm{P})$ \\
\hline His $^{211}-$ Lys $^{247}$ & $4,707.18^{5}$ & $4,389.73$ & $317.45(4 \mathrm{P})$ \\
\hline $\operatorname{Ile}^{248}-\operatorname{Asn}^{262}$ & $1,896.67$ & $1,656.81$ & $239.86(3 \mathrm{P})$ \\
\hline
\end{tabular}

${ }^{1}$ Peptides and fragments from the plasmin digest of bOPN from bovine milk identified by N-terminal sequencing and matrix-assisted laser desorption ionization mass spectrometry (MALDI-MS).

${ }^{2}$ Measured molecular masses $\left(\mathrm{MH}^{+}\right)$determined by MALDI-MS. If nothing else is mentioned, the masses are monoisotopic.

${ }^{3}$ Expected masses $\left(\mathrm{MH}^{+}\right)$were calculated using the GPMAW software (Lighthouse Data, Odense, Denmark).

${ }^{4}$ Difference between measured and expected masses. The number and type of modifications corresponding to the mass difference are given in parentheses ( $\mathrm{P}=$ phosphorylation and $\mathrm{G}=$ glycosylation).

${ }^{5}$ Average molecular masses were determined by MALDI-MS in linear mode.

${ }^{6}$ The C-terminal of the fragment was verified by Asp- $\mathrm{N}$ digestion in $50 \% \mathrm{H}_{2}{ }^{18} \mathrm{O}$.

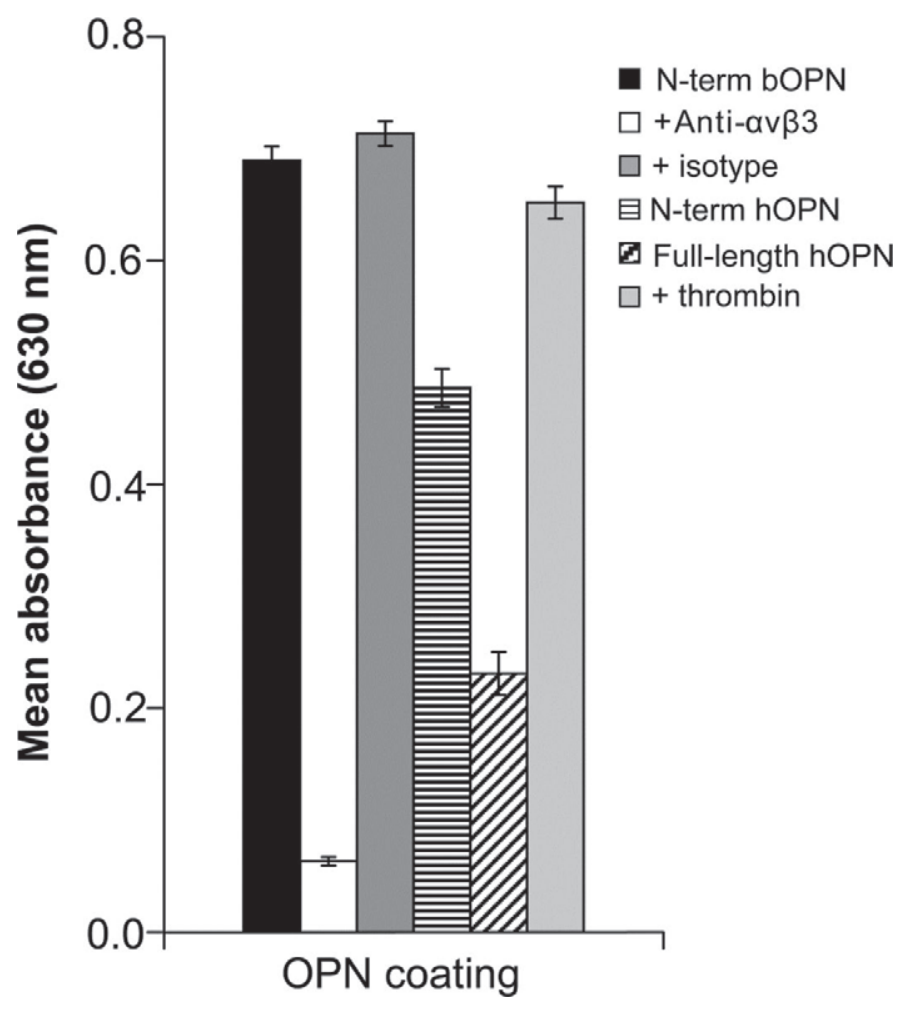

Figure 5. Cell adhesion to osteopontin (OPN). Adhesion to surfaces coated with OPN $(5 \mu \mathrm{g} / \mathrm{mL})$ after preincubation of MDAMB-435 human cancer cells in the presence or absence of $5 \mu \mathrm{g} / \mathrm{mL}$ of an antibody against the $\alpha_{\mathrm{V}} \beta_{3}$-integrin or an isotype IgG control. The N-terminal bovine OPN (bOPN) and human OPN (hOPN) are purified from milk and, therefore, consist as a mix of fragments. Fulllength hOPN is cleaved in vitro with thrombin after purification from milk. The data are expressed as mean $\pm \mathrm{SD}(\mathrm{n}=3)$ and are representative of 3 independent experiments. probably is cleaved close after the $\mathrm{G}^{137} \mathrm{DSVYGLK}^{145}$ sequence (Bissonnette et al., 2012). In the present study, we determined the exact cleavage sites in bOPN. Six N-terminal bOPN fragments generated by cleavage of the Lys ${ }^{145}-$ Ser $^{146}$, $\mathrm{Arg}^{147}-\mathrm{Ser}^{148}$, Lys $^{149}$-Lys ${ }^{150}$, $\mathrm{Phe}^{151}$ $\mathrm{Arg}^{152}, \mathrm{Arg}^{152}-\mathrm{Arg}^{153}$, and $\mathrm{Arg}^{153}{ }^{15} \mathrm{Ser}^{154}$ peptide bonds were identified in bovine milk. These bOPN fragments, which all contain the integrin-binding RGD sequence, could potentially be involved in cell signaling by engaging with integrins in, for example, the gastrointestinal tract.

Plasmin is the most-studied and well-characterized protease in bovine milk where it exists as both an active enzyme and in its zymogen form plasminogen (Kelly et al., 2006; Ismail and Nielsen, 2010). The concentration of plasminogen in bovine milk has been reported to be 0.8 to $2.8 \mu \mathrm{g} / \mathrm{mL}$, whereas the concentration of plasmin is 0.1 to $0.7 \mu \mathrm{g} / \mathrm{mL}$ (Ozen et al., 2003). Plasmin cleavage of different proteins in milk, such as the caseins and component PP3, has been reported (Sørensen and Petersen, 1993b; Wedholm et al., 2008; Pedersen et al., 2012). Plasmin is an alkaline protease that cleaves substrate proteins on the carboxyl side of lysine and arginine residues with a preference for lysine (Weinstein and Doolittle, 1972). Five of the observed cleavage sites in the current study were C-terminal to an arginine or lysine residue, which makes it highly likely that plasmin also is responsible for cleaving bOPN in bovine milk. In vitro analysis showed that plasmin cleaved bOPN at $\mathrm{Lys}^{145}-\mathrm{Ser}^{146}, \mathrm{Arg}^{147}-\mathrm{Ser}^{148}$, and $\mathrm{Arg}^{152}-\mathrm{Arg}^{153}$, corresponding to 3 of the identified cleavage sites in bovine milk. Plasmin cleavage of hOPN has also been observed 
in human milk (Christensen et al., 2010), showing that the enzyme is highly capable of cleaving OPN in milk.

Thrombin and cathepsin $\mathrm{D}$ have been shown to cleave hOPN in vivo and could potentially also cleave bOPN in bovine milk. Thrombin generally has the same specificity as plasmin, although it preferentially cleaves after arginine residues (Weinstein and Doolittle, 1972); however, to our knowledge, thrombin has never been identified in bovine milk, although its expression has been detected by microarray analysis in lactating epithelial cells (Casey et al., 2011). The lysosomal aspartic proteinase cathepsin D is another well characterized milk protease and its concentration in bovine skim milk has been estimated to be approximately $0.4 \mu \mathrm{g} / \mathrm{mL}$ (Larsen et al., 1996). In human milk, cathepsin D has recently been shown to cleave hOPN at Leu ${ }^{151}-\mathrm{Arg}^{152}$ (Christensen et al., 2010), but cleavage of the $\mathrm{Leu}^{144}$-Lys ${ }^{145}$ bond at the corresponding position in bOPN was not observed in this study.

Matrix-assisted laser desorption ionization mass spectrometry is not a quantitative technique, although it seems evident that the peptide GLKSRSKKF ${ }^{151}$ is present in a higher concentration than the peptide GLKSRSKKFR $^{152}$ in the chymotryptic digest of $\mathrm{N}$ terminal bOPN (Figure 2B), especially as arginine side chains are preferably ionized in MALDI-MS, which yield higher ion intensities from arginine peptides than from those that do not contain arginine (Krause et al., 1999). Similarly, the peptide DSVAYGLKSRSKKF ${ }^{151}$ from the Asp-N digests of N-terminal bOPN, showed much higher intensity in MALDI-MS (Figure 2D) and significantly higher absorbance in RP-HPLC (Figure 3A) than peptides representing the C-terminals in other cleaved bOPN forms. Collectively, it seems evident that the major cleavage site in bovine milk OPN is at the carboxyl side of Phe ${ }^{151}$.

The cleavage at $\mathrm{Phe}^{151}-\mathrm{Arg}^{152}$ fits the specificity of a chymotrypsin-type of protease and cleavage at this site has also been reported for OPN from human milk and urine (Christensen et al., 2010). It remains to be shown which proteases are actually responsible for this cleavage. Cysteine protease activity has also been demonstrated in bovine milk, and the presence of cathepsin B has been directly shown (Magboul et al., 2001). Furthermore, secretion into milk of the serine proteases cathepsin $\mathrm{G}$ and elastase has been suggested but not directly shown (Kelly et al., 2006).

Proteolytic cleavage of OPN by plasmin, thrombin, and matrix metalloproteinases has in several studies been shown to improve the ability of OPN to bind cellular integrin receptors, such as $\alpha_{\mathrm{V}} \beta_{3}$ (Agnihotri et al., 2001; Yokosaki et al., 2005; Christensen et al., 2010). In our study, we have shown that the $\alpha_{\mathrm{V}} \beta_{3}$-integrin binds to the N-terminal bovine fragments, predominantly cleaved at the $\mathrm{Phe}^{151}-\mathrm{Arg}^{152}$ bond, with the same high affinity as to the well-characterized hOPN form resulting from thrombin cleavage (Figure 5). This shows that the N-terminal fragments in bovine milk are competently able to signal and interact with integrins. Proteolytic cleavage of other milk proteins such as, for instance, the caseins, lactoferrin, $\alpha-L A$, and component PP3 in milk or the gastrointestinal tract has been reported to increase or alter their biological functions (Pedersen et al., 2012; Lönnerdal, 2013). Similarly, the cleavage of bOPN in bovine milk could be an activation step that leads to the formation of highly bioactive fragments, which then can exert bioactive functions such as signaling via integrins in milk and the gastrointestinal tract.

Osteopontin is highly phosphorylated and exists in full-length and cleaved forms in both bovine and human milk, but several other points exist where the protein differs significantly between the 2 species. For instance, bovine milk only contains 10 to $15 \%$ the amount of OPN found in human breast milk (Schack et al., 2009a). Furthermore, the glycan structures also varies between the species, as bOPN contains simple $\mathrm{O}$-glycans consisting of a disialylated $\mathrm{N}$-acetylgalactosamine (GalNAc)-galactose core, whereas hOPN is decorated by large fucosylated $\mathrm{N}$-acetyllactosamine units (Christensen et al., 2012). The cleavage pattern identified in this study also differs from that of human milk at several points. In breast milk, hOPN can be cleaved at 7 different sites by, for example, cathepsin D and plasmin close to the RGD sequence (Christensen et al., 2010). Plasmin, but not cathepsin D, cleavage was also observed in bovine milk in the current study. In addition, cleavage of OPN on the carboxyl side of Ser ${ }^{153}$ and Ser ${ }^{155}$ was only observed in human milk (Figure 4B). Bovine milk OPN seems to be cleaved mostly after Phe ${ }^{151}$, whereas no apparent cleavage preference existed for a specific site in hOPN. These differences can have significant effect on the ability of bOPN to interact with cells, as single amino acid differences next to the integrin-binding motifs in the protein can have significant effects on its interaction with integrins (Yokosaki et al., 2005; Ito et al., 2009). In the current study, we have shown that cleaved bOPN binds the important $\alpha_{\mathrm{V}} \beta_{3}$-integrin more competently than cleaved hOPN from human milk. This could be of importance, as engagement of $\beta_{3}$-integrin receptors by $\mathrm{N}$-terminal OPN can induce cell spreading and subsequent activation of macrophages and induce expression of IL-12 (Ashkar et al., 2000; Weber et al., 2002).

\section{CONCLUSIONS}

In this study, several bOPN fragments containing the integrin binding $\mathrm{RGD}^{138}$ sequence generated by cleav- 
age in the $\mathrm{Lys}^{145}-\mathrm{Arg}^{153}$ region have been characterized in bovine milk. The predominant endogenous proteases in milk and plasmin appeared to cleave bOPN at 3 of the observed sites; however, cleavage at the Phe ${ }^{151}$ $\mathrm{Arg}^{152}$ bond by an unknown chymotrypsin-like type of protease was found to be the predominant cleavage site. The cleaved bOPN showed similar functional properties in relation to engaging the $\alpha_{\mathrm{V}} \beta_{3}$-integrin as the highly active N-terminal OPN component resulting from thrombin cleavage. Thus, bOPN in bovine milk has the competency to interact with cellular integrin receptors in milk and in the gastrointestinal tract.

\section{REFERENCES}

Agnihotri, R., H. C. Crawford, H. Haro, L. M. Matrisian, M. C. Havrda, and L. Liaw. 2001. Osteopontin, a novel substrate for matrix metalloproteinase-3 (stromelysin-1) and matrix metalloproteinase-7 (matrilysin). J. Biol. Chem. 276:28261-28267. http:// dx.doi.org/10.1074/jbc.M103608200.

Anborgh, P. H., J. C. Mutrie, A. B. Tuck, and A. F. Chambers. 2010. Role of the metastasis-promoting protein osteopontin in the tumour microenvironment. J. Cell. Mol. Med. 14:2037-2044. http://dx.doi.org/10.1111/j.1582-4934.2010.01115.x.

Ashkar, S., G. F. Weber, V. Panoutsakopoulou, M. E. Sanchirico, M. Jansson, S. Zawaideh, S. R. Rittling, D. T. Denhardt, M. J. Glimcher, and H. Cantor. 2000. Eta-1 (osteopontin): An early component of type-1 (cell-mediated) immunity. Science 287:860-864.

Bayless, K. J., and G. E. Davis. 2001. Identification of dual $\alpha_{4} \beta_{1}$ integrin binding sites within a 38 amino acid domain in the N-terminal thrombin fragment of human osteopontin. J. Biol. Chem. 276:13483-13489. http://dx.doi.org/10.1074/jbc.M011392200.

Bissonnette, N., P. L. Dudemaine, C. Thibault, and G. Robitaille. 2012. Proteomic analysis and immunodetection of the bovine milk osteopontin isoforms. J. Dairy Sci. 95:567-579. http://dx.doi. org/10.3168/jds.2011-4750.

Casey, T., H. Dover, J. Liesman, L. DeVries, M. Kiupel, M. VandeHaar, and K. Plaut. 2011. Transcriptome analysis of epithelial and stromal contributions to mammogenesis in three week prepartum cows. PLoS ONE. 6:e22541. http://dx.doi.org/10.1371/journal. pone.0022541.

Chatterton, D. E., J. Rasmussen, C. Heegaard, E. Sørensen, and T. Petersen. 2004. In vitro digestion of novel milk protein ingredients for use in infant formulas: Research on biological functions. Trends Food Sci. Technol. 15:373-383. http://dx.doi.org/10.1016/j. tifs.2003.12.004.

Christensen, B., E. Kläning, M. S. Nielsen, M. H. Andersen, and E. S. Sørensen. 2012. C-terminal modification of osteopontin inhibits interaction with the $\alpha_{V} \beta_{3}$-integrin. J. Biol. Chem. 287:3788-3797. http://dx.doi.org/10.1074/jbc.M111.277996.

Christensen, B., M. S. Nielsen, K. F. Haselmann, T. E. Petersen, and E. S. Sørensen. 2005. Post-translationally modified residues of native human osteopontin are located in clusters: Identification of 36 phosphorylation and five $O$-glycosylation sites and their biological implications. Biochem. J. 390:285-292. http://dx.doi. org/10.1042/BJ20050341.

Christensen, B., T. E. Petersen, and E. S. Sørensen. 2008. Posttranslational modification and proteolytic processing of urinary osteopontin. Biochem. J. 411:53-61. http://dx.doi.org/10.1042/ BJ20071021.

Christensen, B., L. Schack, E. Kläning, and E. S. Sørensen. 2010. Osteopontin is cleaved at multiple sites close to its integrin-binding motifs in milk and is a novel substrate for plasmin and cathepsin D. J. Biol. Chem. 285:7929-7937. http://dx.doi.org/10.1074/jbc. M109.075010.

da Silva, A. P. B., R. P. Ellen, E. S. Sørensen, H. A. Goldberg, R. Zohar, and J. Sodek. 2009. Osteopontin attenuation of dextran sulfate sodium-induced colitis in mice. Lab. Invest. 89:1169-1181. http://dx.doi.org/10.1038/labinvest.2009.80.

Ek-Rylander, B., and G. Andersson. 2010. Osteoclast migration on phosphorylated osteopontin is regulated by endogenous tartrateresistant acid phosphatase. Exp. Cell Res. 316:443-451. http:// dx.doi.org/10.1016/j.yexcr.2009.10.019.

Ge, X., Y. Lu, T.-M. Leung, E. S. Sørensen, and N. Nieto. 2013. Milk osteopontin, a nutritional approach to prevent alcohol-induced liver injury. Am. J. Physiol. Gastrointest. Liver Physiol. 304:G929G939. http://dx.doi.org/10.1152/ajpgi.00014.2013

Holt, C., E. S. Sørensen, and R. A. Clegg. 2009. Role of calcium phosphate nanoclusters in the control of calcification. FEBS J. 276:2308 2323. http://dx.doi.org/10.1111/j.1742-4658.2009.06958.x.

Hoyer, J. R., J. R. Asplin, and L. Otvos. 2001. Phosphorylated osteopontin peptides suppress crystallization by inhibiting the growth of calcium oxalate crystals. Kidney Int. 60:77-82. http://dx.doi. org/10.1046/j.1523-1755.2001.00772.x.

Ismail, B., and S. S. Nielsen. 2010. Invited review: Plasmin protease in milk: Current knowledge and relevance to dairy industry. J. Dairy Sci. 93:4999-5009. http://dx.doi.org/10.3168/jds.2010-3122.

Ito, K., S. Kon, Y. Nakayama, D. Kurotaki, Y. Saito, M. Kanayama, C. Kimura, H. Diao, J. Morimoto, Y. Matsui, and T. Uede. 2009. The differential amino acid requirement within osteopontin in $\alpha_{4}$ and $\alpha_{9}$ integrin-mediated cell binding and migration. Matrix Biol. 28:11-19. http://dx.doi.org/10.1016/j.matbio.2008.10.002.

Kazanecki, C. C., D. J. Uzwiak, and D. T. Denhardt. 2007a. Control of osteopontin signaling and function by post-translational phosphorylation and protein folding. J. Cell. Biochem. 102:912-924. http://dx.doi.org/10.1002/jcb.21558.

Kazanecki, C. C., D. J. Uzwiak, and D. T. Denhardt. 2007b. Control of osteopontin signaling and function by post-translational phosphorylation and protein folding. J. Cell. Biochem. 102:912-924. http://dx.doi.org/10.1002/jcb.21558.

Kelly, A. L., F. O'Flaherty, and P. F. Fox. 2006. Indigenous proteolytic enzymes in milk: A brief overview of the present state of knowledge. Int. Dairy J. 16:563-572. http://dx.doi.org/10.1016/j.idairyj. 2005.10.019.

Keykhosravani, M., A. Doherty-Kirby, C. Zhang, D. Brewer, H. A. Goldberg, G. K. Hunter, and G. Lajoie. 2005. Comprehensive identification of post-translational modifications of rat bone osteopontin by mass spectrometry. Biochemistry 44:6990-7003. http:// dx.doi.org/10.1021/bi050109p.

Kolbach, A. M., O. Afzal, B. Halligan, E. Sorokina, J. G. Kleinman, and J. A. Wesson. 2012. Relative deficiency of acidic isoforms of osteopontin from stone former urine. Urol. Res. 40:447-454. http://dx.doi.org/10.1007/s00240-012-0459-1.

Krause, E., H. Wenschuh, and P. R. Jungblut. 1999. The dominance of arginine-containing peptides in MALDI-derived tryptic mass fingerprints of proteins. Anal. Chem. 71:4160-4165.

Kumura, H., A. Miura, E. Sato, T. Tanaka, and K. Shimazaki. 2004 Susceptibility of bovine osteopontin to chymosin. J. Dairy Res. 71:500-504.

Larsen, L. B., C. Benfeldt, L. K. Rasmussen, and T. E. Petersen. 1996. Bovine milk procathepsin D and cathepsin D: coagulation and milk protein degradation. J. Dairy Res. 63:119-130.

Lönnerdal, B. 2013. Bioactive proteins in breast milk. J. Paediatr. Child Health 49(Suppl. 1):1-7. http://dx.doi.org/10.1111/ jpc.12104.

Magboul, A. A. A., L. B. Larsen, P. L. H. McSweeney, and A. L. Kelly. 2001. Cysteine protease activity in bovine milk. Int. Dairy J. 11:865-872. http://dx.doi.org/10.1016/S0958-6946(01)00126-1.

Nemir, M., D. Bhattacharyya, X. Li, K. Singh, A. B. Mukherjee, and B. B. Mukherjee. 2000. Targeted inhibition of osteopontin expression in the mammary gland causes abnormal morphogenesis and lactation deficiency. J. Biol. Chem. 275:969-976.

Ozen, B. F., K. D. Hayes, and L. J. Mauer. 2003. Measurement of plasminogen concentration and differentiation of plasmin and plasminogen using Fourier-transform infrared spectroscopy. Int. Dairy J. 13:441-446. http://dx.doi.org/10.1016/S0958-6946(03)00055-4.

Pedersen, L. R. L., J. G. Hansted, S. B. Nielsen, T. E. Petersen, U. S. Sørensen, D. Otzen, and E. S. Sørensen. 2012. Proteolytic activa- 
tion of proteose peptone component 3 by release of a C-terminal peptide with antibacterial properties. J. Dairy Sci. 95:2819-2829. http://dx.doi.org/10.3168/jds.2011-4837.

Schack, L., A. Lange, J. Kelsen, J. Agnholt, B. Christensen, T. E. Petersen, and E. S. Sørensen. 2009a. Considerable variation in the concentration of osteopontin in human milk, bovine milk, and infant formulas. J. Dairy Sci. 92:5378-5385. http://dx.doi. org $/ 10.3168 /$ jds.2009-2360.

Schack, L., R. Stapulionis, B. Christensen, E. Kofod-Olsen, U. B Skov Sørensen, T. Vorup-Jensen, E. S. Sørensen, and P. Höllsberg. 2009b. Osteopontin enhances phagocytosis through a novel osteopontin receptor, the alphaXbeta2 integrin. J. Immunol. 182:6943-6950. http://dx.doi.org/10.4049/jimmunol.0900065.

Schnölzer, M., P. Jedrzejewski, and W. D. Lehmann. 1996. Proteasecatalyzed incorporation of ${ }^{18} \mathrm{O}$ into peptide fragments and its application for protein sequencing by electrospray and matrix-assisted laser desorption/ionization mass spectrometry. Electrophoresis 17:945-953. http://dx.doi.org/10.1002/elps.1150170517.

Senger, D. R., C. A. Perruzzi, A. Papadopoulos, and D. G. Tenen. 1989. Purification of a human milk protein closely similar to tumor-secreted phosphoproteins and osteopontin. Biochim. Biophys. Acta 996:43-48.

Sharif, S. A., X. Du, T. Myles, J. J. Song, E. Price, D. M. Lee, S. B. Goodman, M. Nagashima, J. Morser, W. H. Robinson, and L. L. K. Leung. 2009. Thrombin-activatable carboxypeptidase B cleavage of osteopontin regulates neutrophil survival and synoviocyte binding in rheumatoid arthritis. Arthritis Rheum. 60:2902-2912. http://dx.doi.org/10.1002/art.24814.

Sodek, J., B. Ganss, and M. D. McKee. 2000. Osteopontin. Crit. Rev. Oral Biol. Med. 11:279-303.

Sørensen, E. S., P. Højrup, and T. E. Petersen. 1995. Posttranslational modifications of bovine osteopontin: identification of twenty-eight phosphorylation and three O-glycosylation sites. Protein Sci. 4:2040-2049. http://dx.doi.org/10.1002/pro.5560041009.

Sørensen, E. S., and T. E. Petersen. 1993a. Purification and characterization of three proteins isolated from the proteose peptone fraction of bovine milk. J. Dairy Res. 60:189-197.
Sørensen, E. S., and T. E. Petersen. 1993b. Phosphorylation, glycosylation and amino acid sequence of component PP3 from the proteose peptone fraction of bovine milk. J. Dairy Res. 60:535-542.

Sørensen, S., S. J. Justesen, and A. H. Johnsen. 2003. Purification and characterization of osteopontin from human milk. Protein Expr. Purif. 30:238-245.

Wang, K. X., and D. T. Denhardt. 2008. Osteopontin: Role in immune regulation and stress responses. Cytokine Growth Factor Rev. 19:333-345. http://dx.doi.org/10.1016/j.cytogfr.2008.08.001.

Weber, G. F., S. Zawaideh, S. Hikita, V. A. Kumar, H. Cantor, and S. Ashkar. 2002. Phosphorylation-dependent interaction of osteopontin with its receptors regulates macrophage migration and activation. J. Leukoc. Biol. 72:752-761.

Wedholm, A., H. S. Møller, H. Lindmark-Månsson, M. D. Rasmussen, A. Andrén, and L. B. Larsen. 2008. Identification of peptides in milk as a result of proteolysis at different levels of somatic cell counts using LC MALDI MS/MS detection. J. Dairy Res. 75:7683. http://dx.doi.org/10.1017/S0022029907002968.

Weinstein, M. J., and R. F. Doolittle. 1972. Differential specificities of the thrombin, plasmin and trypsin with regard to synthetic and natural substrates and inhibitors. Biochim. Biophys. Acta 258:577-590.

Yamniuk, A. P., H. Burling, and H. J. Vogel. 2009. Thermodynamic characterization of the interactions between the immunoregulatory proteins osteopontin and lactoferrin. Mol. Immunol. 46:23952402. http://dx.doi.org/10.1016/j.molimm.2009.04.024

Yokosaki, Y., N. Matsuura, T. Sasaki, I. Murakami, H. Schneider, S. Higashiyama, Y. Saitoh, M. Yamakido, Y. Taooka, and D. Sheppard. 1999. The integrin $\alpha_{9} \beta_{1}$ binds to a novel recognition sequence (SVVYGLR) in the thrombin-cleaved amino-terminal fragment of osteopontin. J. Biol. Chem. 274:36328-36334.

Yokosaki, Y., K. Tanaka, F. Higashikawa, K. Yamashita, and A Eboshida. 2005. Distinct structural requirements for binding of the integrins $\alpha v \beta 6, \alpha v \beta 3, \alpha v \beta 5, \alpha 5 \beta 1$ and $\alpha 9 \beta 1$ to osteopontin. Matrix Biol. 24:418-427. http://dx.doi.org/10.1016/j.matbio.2005.05.005. 